\title{
Biopolítica, discurso e controle da população pobre
}

\author{
Biopolitics, discourse and control of the poor population
}

\author{
Kátia Menezes de SOUSA \\ Universidade Federal de Goiás(UFG)
}

http://orcid.org/0000-0003-3391-2594

\begin{abstract}
RESUMO: Diante da proliferação de discursos de intolerância e ódio dirigidos contra a população pobre nos últimos anos, responsabilizando-a pela crise econômica e desordem do país, este texto se propõe a problematizar os enunciados e as condutas que envolvem o corpo pobre, atendendo ao objetivo mais amplo que é o de conhecer alguns traços do que somos hoje, do que é nossa sociedade. Essa problematização busca apoio teórico e analítico em Michel Foucault para percorrer os acontecimentos que ligaram a pobreza a uma moral do trabalho, como a conhecemos hoje, sob o escopo do neoliberalismo. As práticas estudadas por Foucault, em "História da loucura", sobre o internamento dos pobres em hospitais gerais e sua liberação já numa sociedade disciplinar, e em seus cursos sobre a governamentalidade biopolítica, apoiada em dispositivos de segurança, constituem as condições para o aparecimento dos discursos que vão revestir a pobreza hoje de um certo valor moral.
\end{abstract}

PALAVRAS-CHAVE: Discurso. Pobreza. Acontecimento. Trabalho. Moral.

ABSTRACT: With the increase of discourses of intolerance and hate directed to poor population in recent years, blaming them for the economic crisis and disorder in the country, this text aims to problematize the statements and behaviors that involve the poor body, taking into account the broader objective to know some traits about who we are today, what our society is. This problematization seeks theoretical and analytical support in Michel Foucault to go through the events that linked poverty to a work ethic, as we know it today, under the scope of neoliberalism. The practices studied by Foucault, in History of madness, on the internment of the poor in general hospitals and their release into a disciplinary society, and in his courses on biopolitical governmentality, supported by security devices, constitute the conditions for the appearance of the discourses that will give poverty today a certain moral value.

KEYWORDS: Discourse. Poverty. Event. Work. Moral.

\section{Introdução}

Já estávamos habituados a pronunciamentos políticos que acusavam a existência da pobreza e firmavam o compromisso de erradicá-la. Por uma constituição cristã, moral ou política, a exteriorização de discursos de normalização da existência da pobreza ou de segregação de grupos pobres não encontrava condições que pudessem possibilitar a sua entrada na rede enunciativa com formulações como as que ganharam visibilidade nas práticas discursivas dos brasileiros nos últimos anos. Diante da farta exposição de discursos de ódio aos direitos conquistados e aos ainda reivindicados pela população economicamente mais vulnerável, ou melhor pobre, este artigo se propõe a 
problematizar os enunciados e as condutas que envolvem o corpo pobre nos dias de hoje, tempo em que estamos diante do impensável na trama política, com o descaso dos projetos e discursos do governo em relação às pautas sociais. Essa problematização encontra sustentação em Michel Foucault (2011a), quando, no texto "O que são as luzes", ele formula a questão da modernidade em Kant e afirma que o discurso deve reconsiderar sua atualidade para nela encontrar seu lugar próprio, para dizer seu sentido e especificar o modo de ação que ele pode exercer no interior dessa atualidade. Nesse sentido, analisar o nosso próprio presente é buscar os sinais nos acontecimentos menos grandiosos e menos perceptíveis, para conceder a eles a significação e o valor importantes que buscamos. Pretendemos, assim, mostrar ao final deste texto que o que faz sentido em torno dos discursos sobre o pobre nos últimos sete anos no Brasil é o entusiasmo ligado a uma disposição moral (FOUCAULT, 2011a) da população.

Como forma de operacionalizar a análise, consideramos os fundamentos foucaultianos demonstrados em "A Arqueologia do Saber" (1995) que remetem, conforme o autor (2003, p. 257) explica, "ao tipo de pesquisa que se dedica a extrair os acontecimentos discursivos como se eles estivessem registrados em um arquivo". O discurso configura-se, assim, como uma série de acontecimentos, sendo nossa tarefa estabelecer e descrever as relações que esses acontecimentos discursivos "mantêm com outros acontecimentos que pertencem ao sistema econômico, ou ao campo político, ou às instituições" (FOUCAULT, 2003, p. 256). Perseguindo o projeto arqueológico de Foucault, o objetivo maior é o de conhecer alguns traços do que somos hoje, do que é nossa sociedade: “[...] os acontecimentos discursivos que se produziram há séculos ou há anos são muito importantes. Somos inextricavelmente ligados aos acontecimentos discursivos. Em um certo sentido, não somos nada além do que aquilo que foi dito, há séculos, meses, semanas..." (FOUCAULT, 2003, p. 258).

Os enunciados que circularam nos últimos anos nos colocam diante de problemas que podem ser refletidos com base em formulações que podem assim ser agrupadas: a existência de um corpo pobre construída e delimitada pelo outro do discurso, que é um não pobre; a existência de um corpo pobre desconstruída e deslocada pelo discurso do mesmo, um pobre que se coloca como não pobre; e a existência de um corpo pobre construída e atribuída, por não pobres e pobres, a um não pobre, mas que será objetivado como um corpo pobre por defender a justiça e as políticas sociais. Mas isso é apenas uma superfície corriqueira no plano do senso comum que pretendo problematizar. 
As regularidades de enunciados que diziam do pobre durante a campanha à presidência da república em 2014, durante o processo de instauração do impeachment e após o golpe e a posse de Michel Temer em 2016 acenavam para a existência de um discurso de desqualificação, de ódio e preconceito ao pobre, que impregnava as práticas discursivas e não discursivas de diferentes domínios. Seria preciso, portanto, pensar arqueologicamente com Foucault sobre as condições de possibilidade desse discurso e sobre a emergência e a disseminação dos enunciados que, além de sustentar e serem sustentados por relações de saber/poder, também, conduziam a população a uma verdade.

De forma bastante resumida, neste trabalho, tentamos acompanhar Foucault (1995, p. 50) em seu fazer analítico, quando considera que a formação dos objetos, em nosso caso a pobreza, "é assegurada por um conjunto de relações estabelecidas entre instâncias de emergência, de delimitação e de especificação", para mostrar como o objeto pobreza, como a conhecemos hoje, encontra seu lugar e sua lei de aparecimento e entra num feixe complexo de relações que não estão presentes no objeto em si, mas que "são estabelecidas entre instituições, processos econômicos e sociais, formas de comportamentos, sistemas de normas, técnicas, tipos de classificação, modos de caracterização" (FOUCAULT, 1995, p. 51).

Como forma de atender a esse propósito, dividimos o texto em duas partes para pensarmos, na primeira parte, na emergência dos discursos sobre o corpo pobre e suas transformações como condição histórica para que dele possamos dizer certas coisas hoje e para que ele apareça em suas relações com outros objetos, sejam elas de semelhança, diferença ou transformação.

A segunda parte se centrará no movimento de mostrar que o discurso aparece como "um bem que coloca, desde sua existência, a questão do poder; um bem que é, por natureza, o objeto de uma luta, e de uma luta política" (FOUCAULT, 1995, p. 139). Considerando que o poder opera através do discurso, e o próprio discurso é um elemento em um dispositivo estratégico de relações de poder (FOUCAULT, 2003), tomaremos a pobreza como alvo de dispositivos que, com suas técnicas de poder voltadas à proteção das vidas, possibilitam que os indivíduos sejam monitorados, contados, comparados e controlados. Após o uso do poder sobre o corpo de um modo individualizador, implementado pelas tecnologias disciplinares, surgirá, sem excluir a disciplina, um poder massificador, que se dirigirá não ao homem como corpo, mas ao homem como espécie, uma nova tecnologia que "se dirige à multiplicidade dos homens, 
não na medida em que eles se resumem em corpos, mas na medida em que ela forma, ao contrário, uma massa global, afetada por processos como o nascimento, a morte, a produção, a doença etc" (FOUCAULT, 1999a, p. 289). É para os discursos sobre essa massa, que é a população, afetada pela pobreza, que vamos olhar, ao considerarmos a forma de poder que Foucault (1999a) chamou de biopolítica da espécie humana.

Os estudos de Foucault em "Nascimento da biopolítica" sobre o liberalismo e o neoliberalismo, como condição de inteligibilidade da biopolítica, nos oferecem uma análise das regras do funcionamento da arte de governar neoliberal, indicando ferramentas para que possamos problematizar a pobreza numa sociedade biopolítica, em que a população são os sujeitos de direito sobre os quais a soberania política é exercida, sendo, portanto, a população aquilo que um governo deve administrar.

As duas seções que seguem têm em vista a existência acumulada dos discursos enquanto traços que subsistiram, ou se transformaram, ou se apagaram no surgimento dos acontecimentos discursivos que envolvem a pobreza no presente, o que requer uma análise, nos termos de Foucault (2000a), que considere tanto a arqueologia como possibilidade de tornar visível o sistema de discurso no qual vivemos, questionando aquilo que é dito entre nós, quanto a genealogia que não seria a descrição dos começos e das sucessões, mas uma forma de estudar as nossas relações com a verdade e com o poder que emergem dos enunciados em determinado momento e lugar. Castro (2009, p. 185) lembra que "arqueologia e genealogia se apoiam sobre um mesmo pressuposto comum: escrever a história sem referir a análise à instância fundadora do sujeito".

\section{A emergência do corpo pobre e suas transformações}

Quando falamos de emergência com Foucault (2000b), não estamos nos referindo à origem, mas à lei singular de um aparecimento num jogo em que forças lutam umas contra as outras, mesmo não pertencendo a um mesmo tempo ou espaço: “ninguém é, portanto, responsável por uma emergência, ninguém pode se atribuir a glória por ela, ela sempre se produz no interstício" (FOUCAULT, 2000b, p. 269). Essa consideração retira da história, do ponto de vista da genealogia, a finalidade de reencontrar as raízes de nossa identidade, a obrigação de demarcar o território único de onde viemos, mas dirige a ela a tarefa de fazer aparecer as descontinuidades que atravessam nosso tempo, nosso espaço e nossa vida.

O nosso ponto de ancoragem para tratar do problema da pobreza é a emergência do Hospital Geral, conforme a descrição feita por Foucault em "História da loucura". 
Compartilhamos com Le Blanc (2013, p. 173) a percepção de que o primeiro grande livro de Foucault "pode ser lido como uma história da pobreza na Idade Clássica". Segundo Le Blanc (2013), a atualidade de Foucault reside na história do hospital geral que, em sua emergência, fez aparecer o louco e o pobre como figuras solidárias. Foucault (2005) lembra que o século XVII criou vastas casas de internamento na Europa, e o hospital geral, em seus propósitos, não se baseava numa ideia médica, mas era uma instância da ordem monárquica e burguesa. Desempenhava um papel de assistência e de repressão ao mesmo tempo, o que conferiu a esse espaço de internamento um poder de segregação ao organizar

$$
\begin{aligned}
& \text { numa unidade complexa uma nova sensibilidade à miséria e aos } \\
& \text { deveres da assistência, novas formas de reação diante dos problemas } \\
& \text { econômicos do desemprego e da ociosidade, uma nova ética do } \\
& \text { trabalho e também o sonho de uma cidade onde a obrigação moral se } \\
& \text { uniria à lei civil, sob as formas autoritárias da coação. }
\end{aligned}
$$

Assim, o internamento se justifica duplamente, como benefício, pela existência do grupo do bem, que é o da pobreza submissa e que age em conformidade à ordem imposta, e como punição, pela existência do grupo do mal, uma pobreza insubmissa e avessa à ordem. Foucault (2005) demonstra com essa oposição que os maus pobres transformam a prática do internamento num empreendimento da repressão, e os bons pobres fazem dela uma obra de assistência. Dessa forma, "a oposição entre os bons e os maus pobres é essencial à estrutura e à significação do internamento" (FOUCAULT, 2005, p. 60). Também, a própria loucura será assim dividida, de acordo com a atitude moral que parece manifestar. Sobre o tratamento moral da miséria, Le Blanc (2013, p. 176) acrescenta que o pobre deixa de ser "uma subjetividade opaca que contém sob seus farrapos as marcas da glória divina" para se tornar "um sujeito reduzido à superfície apenas de suas aparências que atesta sua submissão à nova ordem do hospital geral, ou, ao contrário, revela sua malandragem e sua vida má". A partir desse acontecimento, o pobre será constituído como um sujeito moral, que é atravessado pelo dilema ético de uma adesão à obra de assistência ou de uma recusa a essa ordem e sujeito exposto ao julgamento moral que o exibe em sua verdade.

Ainda, o internamento constitui uma das tentativas de solução a uma crise econômica que afetava o mundo ocidental no século XVII, e o Hospital Geral servirá para colocação dos desempregados e dos vagabundos (FOUCAULT, 2005). Mesmo fora dos períodos de crise, o internamento adquirirá uma função repressiva e uma nova utilidade: "não se trata mais de prender os sem trabalho, mas de dar trabalho aos que 
foram presos, fazendo-os servir com isso a prosperidade de todos" (FOUCAULT, 2005, p. 67). O internamento absorvia os desempregados, ocultando a miséria e evitando os problemas políticos ou sociais de sua circulação, mas já se constituindo como um fracasso, por não segurar o aumento do desemprego e por impor uma ação artificial sobre os preços, com a qual não garantia a proporção entre o custo real dos produtos fabricados ali e as despesas do internamento. Contudo, Foucault (2005, p. 71) analisa que, mesmo com esse fracasso, a era clássica realizou uma experiência irredutível: "a eficácia do trabalho é reconhecida porque é baseada em sua transcendência ética". O poder do trabalho de fazer desaparecer a miséria vai se dar menos por seu poder produtor do que por "uma certa força de encantamento moral [...]: o trabalho nas casas de internamento assume assim uma significação ética" (FOUCAULT, 2005, p. 71-72), ao traçar a relação indissolúvel da exigência econômica e moral e a separação entre trabalho e ociosidade. Podemos dizer, conforme a análise da seção seguinte, que, nos dias de hoje, convivemos com a repulsa moral às políticas de inclusão e aos projetos sociais de governo que visam a diminuir as desigualdades sociais.

A não dissociação entre pobres e loucos na "História da loucura" de Foucault tem seu surgimento nesta época, quando começaram a internar os loucos, reconhecendo seu parentesco com essa população de ociosos, de inúteis para o sagrado labor e para a vida social e os condenando, não pela insanidade, mas por atravessarem "por conta própria as fronteiras da ordem burguesa, alienando-se fora dos limites sacros de sua ética" (FOUCAULT, 2005, p. 73). A pobreza não é mais vista numa dialética da humilhação e da glória, como fora na Idade Média, em que a sensibilidade à miséria estava ligada à glorificação da dor, à salvação pela pobreza e caridade, mas como um efeito da desordem e um obstáculo à ordem (FOUCAULT, 2005). O hospital geral marcou o início da laicização da caridade e da ideia de castigo moral da miséria, que "passa de uma experiência religiosa que a santifica para uma experiência moral que a condena" (FOUCAULT, 2005, p. 59). Diante dessa mudança, a igreja escolhe seu lado se colocando a favor do internamento, justificando seu benefício e a punição com a divisão entre bons e maus pobres. Para ela, a internação, sob a forma de um modelo autoritário, representa o mito da felicidade social, funcionando como uma polícia coerente aos princípios da religião e como uma religião que teria suas exigências cumpridas nas regras e coações da polícia.

O hospital geral funciona bem para a repressão e como forma de administrar os miseráveis, e "durante muito tempo a casa de correção ou os locais do hospital geral 
servirão para colocação dos desempregados, dos sem trabalho e dos vagabundos" (FOUCAULT, 2005, p. 67), marcando, assim, a emergência de uma sociedade disciplinar, mas cumprindo uma função negativa da disciplina, que é parar o mal numa instituição fechada, estabelecida à margem (FOUCAULT, 1987). Le Blanc (2013) mostra que a extensão das instituições disciplinares no século XVIII vai inverter essa imagem negativa numa imagem positiva, que Foucault (1987) qualifica como um dispositivo funcional que deve melhorar o exercício do poder tornando-o mais rápido, como inversão funcional das disciplinas, ramificação dos mecanismos disciplinares e sua estatização. Foucault (2005, p. 78) destaca que a internação, criação institucional do século XVII, vai assumindo "uma amplitude que não lhe permite uma comparação com a prisão tal como esta era praticada na Idade Média", e ganhando "um valor de invenção", ao se constituir como "medida econômica e precaução social".

Em Os anormais, falando sobre a invenção das tecnologias positivas de poder no decorrer do século XVIII, Foucault (2001, p. 59) compara essa substituição de uma disciplina negativa por uma positiva com a lepra e a peste, respectivamente, pelo fato de que, a partir dessa época, o que contou politicamente não foi o velho modelo da lepra, do qual é possível encontrar seu último resíduo "na exclusão dos mendigos, dos loucos, etc., e no grande 'internamento'. [...] a peste substituiu a lepra como modelo de controle político, e é essa uma das grandes invenções do século XVIII”. Ele explica que a reação à lepra foi uma reação negativa, de rejeição e de exclusão, e a reação à peste foi positiva, uma reação de inclusão, de observação, de formação de saber e de multiplicação dos efeitos de poder. Quanto ao grande internamento, a tentativa de fazer com que os internos trabalhassem vai responder a um novo paradigma disciplinar, segundo o qual, como elabora Foucault (1987, p. 174) em "Vigiar e punir", "as disciplinas funcionam cada vez mais como técnicas que fabricam indivíduos úteis". Considerando essa passagem, Le Blanc (2013) escreve que o hospital geral não chega a funcionar como uma instituição disciplinar produtiva, pois não renunciou ao seu sentido disciplinar negativo, mantendo a função negativa de isolar e excluir os mendigos, mesmo tendo pretendido transformar o ocioso em trabalhador.

Assim, conforme Foucault (2001, p. 60), a Idade Clássica inventou um poder que fabrica e age por produção e maximização da produção, um poder ligado a mecanismos para assegurar a formação, o investimento, a acumulação, o crescimento do saber, e “elaborou o que podemos chamar de uma 'arte de governar', precisamente no 
sentido em que se entendia, nessa época, o 'governo' das crianças, o 'governo' dos loucos, o 'governo’ dos pobres e, logo depois, o ‘governo’ dos operários.

Em seu valor funcional, as casas de internamento foram um fracasso, e seu desaparecimento no começo do século XIX, como centros de recepção de indigentes e prisão da miséria, significará seu fracasso final, mas será lugar exclusivo dedicado aos loucos, que se verão separados dos miseráveis, vagabundos e desempregados (FOUCAULT, 2005). De sua leitura da "História da loucura", Le Blanc (2013) resume que a razão de Descartes produzirá o advento do hospital geral, que terá como reposta o gesto de Pinel libertando dali os loucos da companhia dos miseráveis, mas para melhor submetê-los à ordem psiquiátrica do asilo que irá proteger, pelo confinamento, a sociedade dos loucos e os loucos da sociedade. O estatuto médico do novo asilo liberta os pobres, e "a loucura aparece finalmente como a única razão de um internamento cujo profundo desatino ela simboliza" (FOUCAULT, 2005, p.398). O pobre passa fazer parte novamente do corpo da nação, da população. Le Blanc (2013) chama a atenção para o conceito de população, que se tornará tema maior nos cursos de Foucault sobre a biopolítica, já encontrar lugar na História da loucura, quando o pobre, livre do internato, será analisado e considerado necessário para tornar possível a riqueza. Há, assim, uma reabilitação moral do pobre, que designa "uma reintegração econômica e social de sua personagem. [...] o pensamento econômico elabora sobre novas bases a noção de pobreza" (FOUCAULT, 2005, p. 406), que está ligada à rarefação dos alimentos e à situação econômica do comércio, da agricultura e da indústria. Já a população é a força que integra a situação econômica, o movimento produtor de riquezas, posto que é o trabalho do homem que a cria e multiplica. Ao invés de haver internação, seria razoável recolocar toda essa população no roteiro da produção como forma de dividi-la pelos pontos onde a mão-de-obra era mais rara e, assim, "utilizar os pobres, os vagabundos, os exilados e emigrados de toda espécie é um dos segredos da riqueza, na concorrência entre as nações.

O pobre foi reintroduzido na sociedade da qual havia sido expulso pelo internamento, mas agora com uma nova feição. Se havia uma dignidade eminente dos pobres, dando sentido ao ato de caridade na época do internamento, no século XVIII ela vai se transformar em primordial utilidade: "O rico da Idade Média era santificado pelo pobre, o do século XVIII é mantido por este” (FOUCAULT, 2005, p. 410); os pobres não são mais aqueles sujeitos do hospital geral, nem aqueles indivíduos individualizados como sujeito de Deus e pelas práticas da caridade, "mas abstrações ao 
olhar da realidade última que é a população como força de geração de riqueza, a tal ponto que a figura do pobre tende a desaparecer enquanto tal em proveito da noção de pobreza" (LE BLANC, 2013, p. 181). O que se desenha é um deslocamento do pobre como indivíduo, por uma relação de saber e de poder, para uma tensão entre pobreza e população, que esboça uma nova realidade social que irá se construir, num continuum, não menos conflituoso, que vai do pobre sem emprego, mas empregável, ao pobre empregado. Conforme Foucault (1999b, p. 307-308), “a tensão entre o que chamamos de proletariado e subproletariado manifestamente provocou, no final do século XIX, toda uma série de medidas, assim como fez nascer toda uma ideologia. [...] Essa fronteira ameaça esfumar-se com o crescimento do desemprego". No Brasil atual, com o alto índice de desempregados, outra categoria teve mesmo de ser inventada, a de desalentados, grupo daqueles desempregados que não estão à procura de empregos.

No decorrer do século XVIII, com a grade mais fechada dessa população em que se examinavam o modo de investimento e capitalização e as distinções entre as diferentes categorias de infelizes, "o pobre é um dos primeiros a ser apagado e a dar lugar a toda uma série de distinções funcionais (os bons e os maus pobres, os ociosos voluntários e os desempregados involuntários, os que podem e os que não podem fazer algum trabalho)" (FOUCAULT, 2011b, p. 360). A sacralização do pobre é substituída pela análise da ociosidade, de suas condições e efeitos, com o objetivo de tornar a pobreza útil, fixando-a ao aparelho de produção, e de aliviar seu peso para o resto da sociedade. No conjunto de problemas apontados pela análise, o corpo, tanto dos indivíduos quanto das populações, aparece portando novidades, conforme Foucault (2011b), não sendo mais apenas corpos raros ou numerosos, submissos ou indóceis, ricos ou pobres, mas se são utilizáveis, suscetíveis de investimentos rentáveis, com chance de sobrevivência e capazes de aprendizagem eficaz.

Foucault (2011c) explica que, ao longo do século XVIII, o pobre, no interior de uma cidade, era uma condição da atividade urbana e não podia, portanto, ser considerado como um perigo, pois era bastante útil. A partir do segundo terço do século XIX, continua ele, o problema da pobreza começou a aparecer como ameaça e perigo, principalmente pelas revoltas populares desencadeadas contra os sistemas que privavam os mais desprovidos de alimentação e pelos medos políticos e sanitários suscitados pela população proletária durante a pandemia de cólera. Diante dessas e outras razões, o espaço urbano começou a ser dividido em setores ricos e setores pobres. Podemos considerar que foi com base na história da pobreza que Foucault vai encontrando nas 
práticas que analisa que ele pôde sustentar que o capitalismo, que se desenvolveu a partir do final do século XVIII e começo do XIX, socializou um primeiro objeto, o corpo, em função da força produtiva do trabalho. Assim, o controle da sociedade sobre os indivíduos não se efetua mais apenas pela consciência ou pela ideologia, mas também dentro e com o corpo, pois, "para a sociedade capitalista, importava, antes de tudo, a biopolítica, o biológico, o somático, o corporal. O corpo era uma realidade biopolítica" (FOUCAULT, 2011c, p. 405).

\section{Biopolítica, população pobre e produção de riqueza}

No curso de 1978, "Segurança, território e população", encontramos delineados os elementos da arte neoliberal de governar, quando Foucault distingue o dispositivo disciplinar do dispositivo de segurança, define a noção de população, mostra a forma de conduzir do pastorado para chegar à série, segundo ele (2008a, p. 143), "sólida e não dissociada ainda, constituída de três movimentos: governo, população e economia política". Assim, ele introduz a história da governamentalidade, dizendo entendê-la como "o conjunto constituído pelas instituições, os procedimentos, análises e reflexões, os cálculos e as táticas que permitem exercer essa forma bem específica, embora muito complexa, de poder que tem por alvo principal a população, por principal forma de saber a economia política e por instrumento técnico essencial os dispositivos de segurança" (FOUCAULT, 2008a, p. 143). Além disso, ele afirma que a governamentalidade nasceu a partir da pastoral cristã.

No curso "Nascimento da biopolítica", Foucault (2008b) desenvolve um estudo sobre a arte de governar no liberalismo e neoliberalismo como condição de possibilidade de existência da biopolítica. O liberalismo, conforme o autor, coloca o mercado como o lugar de veridição em termos de valor/preço, e a razão governamental o toma como princípio de autolimitação para governar interesses e não mais o corpo do indivíduo ou sua propriedade. Assim, o liberalismo se insere num mecanismo em que a liberdade e a segurança dos indivíduos são vigiadas em torno da ideia de perigo, sendo essa própria arte de governar o gestor dos perigos e dos mecanismos de segurança/liberdade. O lema do liberalismo é "viver perigosamente" (FOUCAULT, 2008b, p. 90) e funciona para condicionar os indivíduos a anteciparem perigos em sua vida; para justificar a extensão dos procedimentos de controle, de pressão e de coerção e vigilância como forma de intervenção; para estimular ou desestimular condutas sem impor por decreto comportamentos ou ações, mas adotando formas de vigilância para 
redução dos riscos do exercício das liberdades individuais e autorizando a liberdade de mercado, se constituindo como um governo do laissez-faire. O governo manipula interesses e as liberdades dos indivíduos, portadores do risco. A crise do liberalismo vai se dar justamente pelas intervenções econômicas realizadas diante do diagnóstico das falhas dos dispositivos "liberógenos" (FOUCAULT, 2008b, p. 93), destinados a produzir liberdade, mas que podem produzir o inverso. $\mathrm{O}$ paradoxo do liberalismo se localiza na dupla exigência: liberdade e segurança. É, como avalia Foucault (2008b), crise também do capitalismo e do dispositivo geral de governamentalidade. O neoliberalismo, assim, vai colocar sob intervenção a individualidade e não a liberdade perigosa do indivíduo.

$\mathrm{Na}$ análise de Doherty (2008, p. 206), com base em Foucault, "foi a fé das 'massas' sob a demanda do capitalismo industrial que começou a minar a formulação clássica do liberalismo", pois a população percebeu que a posse da liberdade não compensava a pobreza, a restrição econômica e a desintegração social. "As velhas práticas liberais da filantropia e da regulação falharam como resposta à condição do 'pobre urbano pauperizado"”.

Como num regime liberal, o neoliberalismo não intervém sobre os efeitos do mercado, mas diferentemente do liberalismo, o governo neoliberal não tem de corrigir os efeitos destruidores do mercado sobre a sociedade; mas somente intervir nessa sociedade, para que os mecanismos concorrenciais possam ter o papel regulador (Foucault, 2008b). O homo oeconomicus que se quer reconstituir não é o homem da troca, o homem consumidor, mas o homem da empresa e da produção. Assim, trata-se de generalizar, multiplicar, difundir a forma empresa no interior do corpo social; fazer do mercado, da concorrência, da empresa o poder enformador da sociedade e de obter uma sociedade indexada na multiplicidade e na diferenciação das empresas. A individualidade aparece na racionalidade política neoliberal como um princípio de dispersão interna da população. Seguindo as explicações de Foucault, Sampaio (2019) lembra que a sociedade é concebida como um conjunto pulverizado de indivíduos que, como empresas em um mercado, devem concorrer perpetuamente entre si, já que é a concorrência entre os indivíduos que pode governar seus desejos e fazer com que todos persigam seus interesses.

Foucault (2008b) comenta que a política social no neoliberalismo não pode adotar a igualdade como objetivo, mas deve deixar a desigualdade agir, fazer funcionar as desigualdades, que não são produto do funcionamento de mercado, mas gestadas pela 
própria sociedade. Assim, é preciso atuar sobre a sociedade para evitar que esses desiquilíbrios retirem os indivíduos dos jogos econômicos do mercado.

Os fundamentos do mercado podem nos guiar a uma forma de entendimento da emergência de discursos de ódio que se espalharam no Brasil, principalmente pelas redes sociais, após as manifestações de 2013, que se iniciaram como um protesto pelo aumento das tarifas do transporte público, mas que se estenderam a outros temas, como corrupção política, má qualidade dos serviços públicos, gastos públicos com os grandes eventos esportivos e que ficaram marcadas pela repetição do slogan "O povo acordou", anunciando o sentimento de uma população que se sentiu enganada pelos discursos de defesa das minorias e pelas políticas sociais apoiadas pelo governo do Partido dos Trabalhadores (PT) e amedrontada diante da existência da crise econômica e da possibilidade de recessão. Em cartazes nos movimentos de rua e em posts nas redes sociais, assistimos à desqualificação moral dos programas sociais do governo, como o Bolsa-Família, o Minha Casa, Minha Vida e o Auxílio Reclusão, que passaram a ser vistos como um mau exemplo capaz de incentivar a produção de vagabundos e desocupados que sobreviveriam às custas dos "homens de bem", "que trabalham". Foucault mostra que a política social neoliberal se organiza como uma assistência social com o objetivo de garantir o mínimo existencial para os assistidos de forma que eles possam participar voluntariamente dos jogos concorrenciais. Esse mínimo existencial, que é a última camada de assistência das práticas de governo, precisa garantir que não haja indivíduos excluídos completamente dos jogos do mercado. $\mathrm{O}$ indivíduo, não participando dos jogos de concorrência, estaria fora também do governo e seria, assim, um desgovernado, um perigoso. Sampaio (2019) destaca que a figura do excluído nos jogos do mercado é indesejável, insegura, arriscada, perigosa.

Sendo a sociedade organizada como um conjunto de empresas, onde cada uma delas busca seus próprios interesses, além da categoria operatória da concorrência, essa sociedade é submetida às regras da teoria do capital humano. Ao substituir o homo oeconomicus da troca por um homo oeconomicus empresário de si mesmo, o neoliberalismo faz com que o indivíduo seja ele próprio seu capital, seja para si mesmo seu produtor e a fonte de sua renda. Formar capital humano significa formar uma espécie de competência-máquina que vai produzir renda, o que demanda a retomada das discussões sobre o trabalho para explorar as razões empíricas precisas e concretas que levam alguém a trabalhar. Uma renda, diz Foucault (2008b, p. 308), é o produto de um capital. Assim, "o trabalho não é uma mercadoria reduzida por abstração à força de 
trabalho e ao tempo durante o qual ela é utilizada"; o trabalho comporta um capital, ou seja, uma aptidão, uma competência, é uma máquina que tem duração de vida, pode se tornar obsoleta e vai envelhecer. Portanto, se o indivíduo não é bem-sucedido economicamente, o problema deve ser visto em termos de insuficiência de investimento do capital humano, de rompimento com o modelo de concorrência perpétua para garantia de que cada indivíduo persiga seus próprios interesses. Logo, o questionamento dos programas sociais do PT, com palavras de ordem denunciando que o dinheiro dos impostos do "cidadão de bem" estava sendo usado para sustentar vagabundos, demonstra uma não aceitação do rompimento com as regras de conduta de mercado, com a disciplina exigida pela competição e com a moral que separa os que investem no capital humano daqueles que não quiseram seguir os valores da empresa de si mesmo, sendo, por isso, os culpados.

A vingança não para por aí, e vamos ter notícias, nesta mesma época já referida, que constituirão, numa regularidade discursiva, a indignação, por parte dos empresários de si, com a presença de corpos pobres em lugares que tradicionalmente eram ocupados pelos endinheirados, como aeroportos, certos shopping centers, resorts, as ruas de Nova York etc. (SAFATLE, 2018, p. 149) comenta que a compreensão da corporeidade como espaço de um empreendimento de si conforma o corpo a uma ideia de "propriedade a ser cuidada a partir da lógica dos investimentos e das rentabilizações, como expressão básica de um individualismo possessivo". Ainda conforme o autor é necessário que a experiência subjetiva seja organizada em seu modo de relação com a diferença; uma organização que deve ser corporalmente sentida.

A derrubada do governo petista, visto como defensor das políticas sociais, e a posse de Michel Temer, que num golpe compactuou com a ideia apregoada pela mídia defensora do mercado financeiro de que "não se deveria dar o peixe, mas ensinar a pescar", abriram espaço para que não só as pessoas comuns expressassem a sua corporeidade ressentida, mas também os políticos que assumiram o governo se sentissem muito à vontade para atacarem os corpos pobres. São muitas as ocorrências e vamos lembrar apenas de algumas:

Maioria dos pacientes que procuram atendimento em unidades de atenção básica da rede pública apenas "imagina" estar doente, mas não está (ministro da Saúde Ricardo Barros em 16 jul. 2016).

Nunca cuidei dos pobres, não sou São Francisco de Assis. Até porque a primeira vez que tentei carregar um pobre 'pra' dentro do meu carro eu vomitei por causa do cheiro", falou o candidato. (Prefeito de Curitiba Rafael Greca, setembro de 2016). 
Precisamos de turistas que saibam valorizar e cuidar do que temos para oferecer, mesmo que precise pagar mais por isso. É o valor de um lugar lindo como esse. E esse turista entende se tiver que pagar mais para entrar na cidade organizada. Estamos em busca disso e vamos alcançar" (Prefeito de Cabo Frio, Marquinho Mendes sobre reajuste tarifário para os ônibus de excursão em 30 jan. 2017).

Marquezelli disse, ainda, que seus filhos vão estudar em universidade porque têm condições de pagar. "Tem que gastar o que tem. $\mathrm{O}$ contribuinte brasileiro não aguenta mais pagar (...) Tem de cortar universidade, tem de cortar. O governo vai se preocupar com o ensino fundamental. Quem puder pagar vai ter de pagar. Meus filhos vão pagar", declarou (deputado Nelson Marquezelli (PTB-SP) em 16 out. 2016).

“Às vezes me sinto a filha da empregada pobre, mas gostosa. Só serve pra comer e ... (deputado federal Celso Jacob em março de 2017).

Se ele [policial] for abordar uma pessoa [na periferia], da mesma forma que ele for abordar uma pessoa aqui nos Jardins [região nobre de São Paulo], ele vai ter dificuldade. Ele não vai ser respeitado", disse. "Da mesma forma, se eu coloco um [policial] da periferia para lidar, falar com a mesma forma, com a mesma linguagem que uma pessoa da periferia fala aqui no Jardins, ele pode estar sendo grosseiro com uma pessoa do Jardins que está ali, andando", complementou. (Em agosto de 2017, tenentecoronel Ricardo Augusto Nascimento de Mello Araújo, 46, o novo comandante da Rota, a tropa de elite da PM (Polícia Militar) de São Paulo).

Baseando-se em Foucault, a americana Wendy Brown (2019a, p. 20) lembra que a racionalidade neoliberal "coloca sob um viés econômico cada esfera e empenho humano e substitui um modelo de sociedade concebida e organizada como mercados, com Estados orientados pelas necessidades do mercado". Os princípios dessa racionalidade "permeiam os locais de trabalho, as escolas, os hospitais, as academias, as viagens aéreas, o policiamento e toda forma do desejo e decisões humanas", na medida em que a racionalidade neoliberal se transforma em nosso senso comum generalizado.

Dessa forma, torna-se compreensível o fenômeno que hoje é conhecido sob a expressão "pobre de direita" que não se convence de sua condição e cobra do Estado as mesmas pautas reivindicadas pelos abonados, indo para as ruas manifestar a favor da reforma da previdência, do abuso de autoridade, da privatização das universidades federais, por exemplo. Sampaio (2019, p. 80) analisa que o resultado da implantação da política social neoliberal é uma cisão entre os pobres: “Já não se trata de separar os ricos dos pobres, mas sim os assistidos dos não assistidos". Os assistidos são os pobres e culpados pela crise econômica do país.

Outro fenômeno a ser considerado é a transformação de indivíduos, com capital humano adquirido, em corpos pobres, pelo fato de lutarem pela justiça social, como é o caso do ex-presidente Lula, que teve sua imagem construída por seus opositores e pela 
mídia para ganhar em seu corpo as marcas do pobre que ousou morar num palácio e comandar um reino. Houve, assim, um forte investimento na produção de enunciados e imagens que recuperavam a história de pobreza de Lula, sua origem nordestina, sua formação escolar incompleta, sem diploma de curso superior, que aparecia hiperbolizada pelo tratamento "analfabeto". Além disso, Lula foi torneiro mecânico e sindicalista. Se Lula foi deputado federal e presidente da república por oito anos, isso não interessa. A recorrência a termos e expressões, como chefe da quadrilha, ladrão, atribuídos a Lula em publicações de redes sociais e em cartazes das manifestações, ganha a adesão de uma enorme parcela da população que, num jogo de interesses, sem comprovações das acusações, reproduz enunciados que confirmam uma subjetividade marcada pelas estratégias de concorrência e pelo individualismo do empreendedorismo de si mesmo. Houve várias acusações que não se sustentaram, mas produziram efeitos para construção da verdade sobre Lula, como a acusação de que havia roubado objetos de valor do palácio, quando terminou seu mandato. A desqualificação do pobre foi dirigida a ele por meio de enunciados que o denunciavam como pinguço ou por enunciados que sugerem ser ele um carente faminto ou um acomodado que não gosta de trabalhar, quando da sua recusa em sair da prisão por progressão da pena, em que pudemos ver enunciados que diziam que ele queria ficar na prisão, porque lá tinha comida garantida sem precisar trabalhar para consegui-la. Foi preciso ser transformado em pobre para que o discurso de criminalização, de intolerância e ódio funcionasse no imaginário da coletividade. Aliás, a publicação de uma mensagem irônica do ex-prefeito do Rio de Janeiro, Eduardo Paes em 2016, ao ex-presidente Lula, confirma a construção desse corpo pobre: "Agora, da próxima vez, o senhor me para com essa vida de pobre, com essa tua alma de pobre, comprando esses barcos de merda, sitiozinho vagabundo".

A generalização da forma econômica no neoliberalismo funciona como princípio de decifração das relações sociais e dos comportamentos individuais, demonstra Foucault (2008b). É no ponto de cruzamento entre uma concepção empírica do sujeito de interesse e as análises dos economistas que será possível definir um sujeito de interesse, cuja ação terá valor multiplicador e benéfico pela própria intensificação do interesse, e é isso que caracteriza o homo oeconomicus.

Wendy Brown (2019a) analisa a racionalidade neoliberal nos Estados Unidos e constata que ela ampliou e aprofundou seu controle, e o princípio de que se deve proteger a liberdade pessoal contra a suposta coerção da vida política desenvolveu-se concretamente tanto na legislação quanto no discurso popular, sendo esse princípio 
mobilizado pelo direito de contestar normas de igualdade, tolerância e inclusão em nome da liberdade e da escolha. Seguindo sua reflexão, concordamos que, quando a esfera protegida, pessoal, é ampliada, quando o social é aviltado e o político demonizado, a animosidade individual e os poderes históricos do domínio dos homens ricos e brancos são legitimados e liberados. Afinal, "Ninguém deve nada a ninguém" (BROWN, 2019a, p. 30), ou como decreta a famosa frase de Margareth Thatcher "não existe essa coisa, a sociedade", já que a expansão da competência do privado tende a restringir o alcance da democracia em nome da liberdade, a atacar os valores e as práticas que sustentam os laços e a igualdade sociais, operando pela exclusão, pela hierarquia e de forma até autoritária.

Apresentando as ideias do intelectual neoliberal Friedrich Hayek, também estudado por Foucault (2008b), Brown (2019b) fala da hostilidade de Hayek em relação ao social que, para ele é o atestado de todas as tentativas mal concebidas de controle da existência coletiva, o símbolo da tirania. Ainda, em seus argumentos, defende que o mercado e a moral "perduram e são válidos porque surgem 'espontaneamente', evoluem e se adaptam 'organicamente', unem os seres humanos independentemente das intenções e estabelecem regras de conduta sem depender da correção ou punição estatais" (BROWN, 2019b, p. 44). O mercado e a moral, para Hayek, revelam, assim, a verdadeira natureza da justiça que é sua preocupação com a conduta, e não com efeitos ou resultados. Para ele, os sistemas morais tradicionais se assemelham aos mercados por estabelecerem uma ordem desprovida de projeto prévio e situarem a justiça nas regras e não nos resultados.

\section{Considerações Finais}

Este artigo tomou como proposta a problematização dos enunciados e das condutas que envolvem o corpo pobre nos dias de hoje e, como objetivo maior, conhecer alguns traços do que somos hoje, do que é nossa sociedade. Também, sinalizamos, com Foucault (2011a), que não são os grandes acontecimentos que fazem sentido nas transformações e apresentamos a ideia de que o que faz sentido em torno dos discursos sobre o pobre nos últimos anos no Brasil é o entusiasmo ligado a uma disposição moral da população.

Disposição moral historicamente construída, conforme nos foi possível perceber nos acontecimentos menores e cotidianos que possibilitaram e justificaram o internamento dos pobres no hospital geral e o seu retorno à sociedade, cujas práticas 
discursivas irão se assentar em julgamentos morais. Se na Idade Média, com a experiência religiosa, a pobreza e a riqueza cantavam, no mundo, o mesmo poder absoluto de Deus (FOUCAULT, 2005), estando a primeira ligada ao castigo e à predestinação e a segunda à glória e à caridade, na era clássica, a concepção moral irá separá-las pela relação entre a desordem e a ordem. Com a obrigação do trabalho nos internatos, novas significações serão atribuídas à pobreza com os valores éticos ligados à importância dada à obrigação do trabalho (FOUCAULT, 2005). Já fora dos internatos, mas com a obrigação do trabalho, os pobres serão divididos entre úteis e inúteis, conforme atendam às técnicas do poder disciplinar e mais tarde, sob os dispositivos de poder de uma biopolítica, o pobre será dividido entre empregável e não empregável, como um elemento intercambiável da população, considerada uma força de geração de riqueza. O trabalho será reintroduzido no campo da análise econômica e fará parte da conduta econômica de quem trabalha (FOUCAULT, 2008b).

Além disso, em nome de um dispositivo de segurança, que funciona como instrumento técnico da economia política que surge com a biopolítica e o liberalismo, hoje, podemos dizer, que há o ressurgimento do espectro do indivíduo perigoso, como aquele que não se sabe o que fazer com ele, do vagabundo, como aquele que depende dos auxílios do governo. O dispositivo de segurança se articula ao modo neoliberal de governar e à gestão biopolítica da população que será responsabilizada, culpabilizada e obrigada, quase moralmente, pela antecipação dos riscos e pela busca por valores "apresentados sob a forma de um pseudo "cuidado de si' impositivo" (CAPONI, 2016, p. 244). A moral continua sendo sustentada pelo valor do trabalho, mas agora individualizada, já que o homem é ele próprio seu capital. Nesse sentido, Foucault (2008b) demonstra que o escopo da política neoliberal se constitui pela multiplicação da forma 'empresa' no interior do corpo social, e a governamentalidade, a maneira como se conduz a conduta dos homens, funciona numa grade da política econômica para a gestão de todo corpo social. É o que ele chama de razão de moralidade.

A explicitação sem pudores de discursos de intolerância e ódio aos pobres nos últimos anos no Brasil pode ser entendida como uma reação da crença no capital humano e nas práticas de concorrência e competição como incentivo para a capacidade produtiva do indivíduo. Assim, o pobre aparece como aquele que não investe em seu capital humano e quer escorar naquele que é um empreendedor de si, um investidor em suas capacidades, um competidor de sucesso. Afinal, é essa a subjetividade produzida pelo neoliberalismo, em que a concorrência deve agir economicamente e organizar o 
cenário político e moral (FOUCAULT, 2008b). Também, encontramos, nessa mesma ordem empresarial, a explicação para o pobre não querer se assumir como tal e demonstrar, em sua conduta, a ideia de que o pobre é o outro e é o culpado, assumindo, assim, uma forma de subjetivação que permite a ele se ver e se comportar como um assalariado capitalista que não é um proletário (FOUCAULT, 2008b). E ainda, essa forma de subjetivação, construída numa economia de mercado, permite a associação da pobreza aos defensores das políticas e dos projetos sociais no governo.

É bem como assinala Brown (2019b), há um assalto neoliberal ao social, juntamente com sua identificação do poder com a coerção, resultado da reformatação do liberalismo. O neoliberalismo faz uma crítica da sociedade e da justiça social em nome da liberdade e das normas morais tradicionais e segundo a convicção de que a vida é determinada pela genética, responsabilidade pessoal e competição de mercado, sendo o social, o inimigo da liberdade. Nesse sentido, o ataque ao social estimula essa liberdade identificada com o neoliberalismo, anulando a possibilidade de igualdade e se constituindo como um ataque agressivo à democracia. O apagamento do social, além de propagar a ideia de que impostos são roubo e não uma forma de sustentar vidas comuns e obras públicas, além de atribuir aos pobres a culpa por sua condição, faz com que se tornem invisíveis as desigualdades sociais geradas pelos legados da escravidão, do colonialismo e do patriarcado. Os valores morais são, portanto, um complemento essencial aos mercados livres, mas como a economia de mercado é vazia de significado moral, é necessário um programa político-moral conservador para compensar seus efeitos na população, para coibir as liberdades, mas que acabou por instrumentalizá-las como feras indomadas à caça dos que rompem o pacto com a obrigação do trabalho, com o empreendedorismo de si e com a concorrência de mercado.

\section{REFERÊNCIAS}

BROWN, W. O Frankenstein neoliberal: liberdade autoritária nas democracias do século XXI. In: RAGO, M. e PELEGRINI, M. (Org.). Neoliberalismos, feminismos e contracondutas: perspectivas foucaultianas. São Paulo: Intermeios, 2019a.

$2019 b$.

Nas ruínas do neoliberalismo. São Paulo: Editora Filosófica Politeia,

CAPONI, S. Viver e deixar morrer: Biopolítica, risco e gestão das desigualdades. In: NALI, M. e MANSANO, S.R.V (Org.). Michel Foucault: desdobramentos. Belo Horizonte: Autêntica, 2016.

CASTRO, E. Vocabulário de Foucault: um percurso pelos seus temas, conceitos e autores. Belo Horizonte: Autêntica, 2009. 
DOHERTY, R. A. Uma política educacional criticamente formativa: Foucault, discurso e governamentalidade. In: PETERS, A. e BESLEY, T. (Org.). Por que Foucault? novas diretrizes para pesquisa educacional. Porto Alegre: Artmed, 2008.

FOUCAULT, M. O que são as luzes? In: FOUCAULT, M. Arte, epistemologia, filosofia e história da medicina. Rio de Janeiro: Forense Universitária, 2011a. (Ditos e escritos; 7).

A política da saúde no século XVIII. In: FOUCAULT, M. Arte, epistemologia, filosofia e história da medicina. Rio de Janeiro: Forense Universitária, 2011b. (Ditos e escritos; 7).

O nascimento da medicina social. In: FOUCAULT, M. Arte, epistemologia, filosofia e história da medicina. Rio de Janeiro: Forense Universitária, 2011c. (Ditos e escritos; 7).

Segurança, território, população. São Paulo: Martins Fontes, 2008a.

. Nascimento da Biopolítica. São Paulo: Martins Fontes, 2008a.

História da loucura: na idade clássica. São Paulo: Perspectiva, 2005.

Diálogo sobre o poder. In: FOUCAULT, M. Estratégia, poder-saber.

Rio de Janeiro: Forense Universitária, 2003. (Ditos e escritos; 4).

Os anormais. São Paulo: Martins Fontes, 2001.

Sobre as maneiras de escrever a história. In: FOUCAULT, M.

Arqueologia das ciências e história dos sistemas de pensamento. Rio de Janeiro: Forense Universitária, 2000a. (Ditos e escritos; 2).

. Nietzsche, a genealogia, a história. In: FOUCAULT, M. Arqueologia das ciências e história dos sistemas de pensamento. Rio de Janeiro: Forense Universitária, 2000b. (Ditos e escritos; 2).

. Em defesa da sociedade. São Paulo: Martins Fontes, 1999.

. Entrevista com Michel Foucault. In: FOUCAULT, M. Problematização do sujeito: psicologia, psiquiatria e psicanálise. Rio de Janeiro: Forense Universitária, 1999b. (Ditos e escritos; 1).

. Vigiar e punir: nascimento da prisão. Petrópolis: Vozes, 1987.

- A arqueologia do saber. Rio de Janeiro: Forense Universitária, 1995.

LE BLANC, G. História da loucura na idade clássica: uma história da pobreza. In:

MUCHAIL. S. T.; FONSECA, M. A.; VEIGA-NETO, A. O mesmo e o outro: 50 anos de História da loucura. Belo Horizonte: Autêntica, 2013.

SAFATLE, W. O circuito dos afetos: corpos políticos, desamparo e o fim do indivíduo. Belo Horizonte: Autêntica Editora, 2018.

SAMPAIO, Pedro Ivan Moreira de. Indivíduo: começo, meio e fim do liberalismo. In: RAGO, M. e PELEGRINI, M. (Org.). Neoliberalismos, feminismos e contracondutas: perspectivas foucaultianas. São Paulo: Intermeios, 2019. 